\title{
Spirits having flown
}

\section{S Hancocks, OBE*}

\author{
Talk spirits in a dental context and one is usually drawn into white, \\ methylated and COSHH regulations. But should it be so, or should we \\ take a step beyond for a change?
}

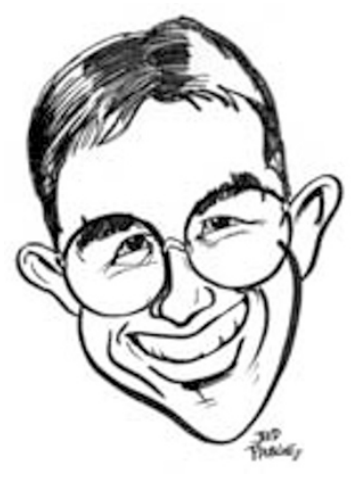

That St. Apollonia is the patron saint of toothache sufferers is one of those interesting' facts that we are all pleased to pick up at dental school. It seems excitingly romantic that 'we' should have a patron saint attached to what we do. A wonderful piece of cocktail party small talk too, not that one attended many undergraduate cocktail parties of course but it was a fascinating thing to know just in case. The sort of nugget of information to introduce on a particularly tedious car journey perhaps, with distant relatives.

As Watford Gap Service Station blurred past in a flurry of spray from the rear wheels of a juggernaut, you could casually say, 'we learned a fascinating thing the other day at dental school. Apparently there is even a patron saint of toothache sufferers.' Cousins twice removed would look up momentarily from their martial arts magazines, aged aunts would nod knowingly before glancing at Northampton in the rain; the relative and the motorway being of course quite open to individual variation.

So why do I mention the goodly Saint at all? Well, odd as it may seem, something recently made me stop and wonder if one was enough. Don't get me wrong, this hasn't been inspired by greed or an avaricious attempt to claim more than dentistry's fair share of the saintly host, only that nowadays dentistry is so much not only to do with toothache. It seems a shame therefore that in the circles of the spiritual, divine and righteous whenever dentistry is mentioned it is still represented with medieval images of pain and torture.

Dentistry has moved on to such an extent and in so many different areas that questions surely need to be asked about the amount of 'cover' that can be provided by one hallowed personage on her own. Not that I doubt for a moment the o'reaching powers of the lady in question, only the extent to which the territory has increased. The panoply after all, is large. There's specialism and aesthetic dentistry, there's infection control and anti-smoking thera- pies, there's continuing professional development and implants and all completely under-represented in the saint department.

Just think of all the wasted opportunities to represent prevention alone, Saint Bisphenol of the Fissure Sealants or Saint Reticulation of Water Fluoridation to mention but two. And what fine, stained-glass centrepieces they could make in the decorative eye of a modern artist. Nor do we utilise at all the spiritual side of dental life, or dental after-life to be more precise. Not infrequently do we see or read of 'ordinary' folk who are in contact with the spirit world and who are guided by Mozart to write another symphony when all they know of music is the ineffectual blowing of a mouth organ. A

\section{Saint Bisphenol of the Fissure Sealants or Saint Reticulation of Water Fluoridation... what fine, stained- glass centrepieces they could make}

baker, barely used to lifting a pen beyond the scribbling of 'a crusty farmhouse and two cobs' inspired by the Bard from beyond the grave to create an award winning sequel to the Scottish play, 'Macbeth 2 - the vengeance returns'. But where in all this are the lost souls of famous dentists? Why is no one moved by a clairvoyant to extend Black's cavity classification under the watchful controlling influence of the spirit of GV himself? Why no rural labourer plucked from obscurity and agitated by medium-moderated creativity into discovering new aspects of Tome's processes by the eponymous consciousness walking free? Of course one understands that saints and deities aren't just created overnight, as it were, so it may be that we have to look to other solutions to provide the necessary credence. There must surely be the possibility of creating a sub-committee of something or another that would be able to look into this with maximum efficiency. It may be possible, for example, to enlist the help of earthly religious celebrities to front-up various sectional and minority groups within dentistry. Admittedly, this might not provide quite the same heavenly gravitas, but at least it might spur a good measure of healthy public relations opportunities and the sort of 'profile' that is so badly needed for some of these apparently sectional interests.

Television, the spirit of the age in so many ways, may provide the clue. Appeals, for example. You know, the sort of ten minute tug at the heart-strings aired on Sunday evenings around the time of the children's serial and the hymn singing programmes, which incidentally, mysteriously always seem to come from somewhere in north Yorkshire or mid-Wales. Picture the scene. Well known TV personality walks towards the camera across a beautiful landscape scattered with freshly erupted primroses, or golden carpeted with fallen leaves (depending on season), leans on handily-available rustic wall or solid oak, but deeply weathered gate, smiles and begins: 'Good evening. Dental implants, have you ever stopped to consider the enormous effects on people's spirituality that this modern technological breakthrough can have?'... or, 'Strange as it may seem there are people, even in this great nation of ours today, who do not know the true meaning of white fillings.'

Indeed, there seems no end to the possibilities of freeing the dental spirit, exploring the outer reaches of oral consciousness and refreshing our minds and bodies with matters not of this world. St Apollonia has been out there alone too long, she desperately needs some help. 